NBER WORKING PAPER SERIES

WHEN SHOULD FIRMS INVEST IN OLD CAPITAL?

Boyan Jovanovic

Working Paper 14000

http://www.nber.org/papers/w14000

NATIONAL BUREAU OF ECONOMIC RESEARCH

1050 Massachusetts Avenue

Cambridge, MA 02138

May 2008

I thank Jess Benhabib, Michele Boldrin, Bart Hobijn, Hyeok Jeong, Matthias Kredler, Omar Licandro, Dmitriy Stolyarov, Gianluca Violante, and especially Jeremy Greenwood for comments and the NSF and the Marion Ewing Kauffman Foundation for support. The views expressed herein are those of the author(s) and do not necessarily reflect the views of the National Bureau of Economic Research.

NBER working papers are circulated for discussion and comment purposes. They have not been peerreviewed or been subject to the review by the NBER Board of Directors that accompanies official NBER publications.

(C) 2008 by Boyan Jovanovic. All rights reserved. Short sections of text, not to exceed two paragraphs, may be quoted without explicit permission provided that full credit, including $\odot$ notice, is given to the source. 
When Should Firms Invest in Old Capital?

Boyan Jovanovic

NBER Working Paper No. 14000

May 2008

JEL No. D21

\section{$\underline{\text { ABSTRACT }}$}

This paper studies optimal investment policies when the production function depends on capital of various vintages. In such an environment it is natural to ask whether the firm will invest in old-vintage capital at all. In this paper I derive such a condition. Predictably, investment in old capital takes place if the elasticity of substitution between old and new capital is low, and when the depreciation of capital is high. But other parameters such as the rates of technological progress and depreciation matter as well.

Boyan Jovanovic

New York University

Department of Economics

19 W. 4th Street, 6th Floor

New York, NY 10012

and NBER

Boyan.Jovanovic@nyu.edu 


\title{
When Should Firms Invest in Old Capital?*
}

\author{
Boyan Jovanovic ${ }^{\dagger}$
}

May 13, 2008

\begin{abstract}
This paper studies optimal investment policies when the production function depends on capital of various vintages. In such an environment it is natural to ask whether the firm will invest in old-vintage capital at all. In this paper I derive such a condition. Predictably, investment in old capital takes place if the elasticity of substitution between old and new capital is low, and when the depreciation of capital is high. But other parameters such as the rates of technological progress and depreciation matter as well.
\end{abstract}

\section{Introduction}

This paper studies a production function that has capital stocks of various vintages as its arguments. Different vintages of capital participate and interact in the same production process for output. The paper seeks to characterize the direction of investment - should that investment be in new vintages, old vintages, or both?

A second class of papers emphasizes a technological specificity of capital and each capital type may have different vintages created. Chari and Hopenhayn (1991) introduce the concept of different technologies within which there are vintages of technology-specific human capital, and then they analyze a special case in which output depends on the employment of old capital and new capital specific to that technology. Boldrin and Levine $(2001,2002)$ and Boldrin and Fernandez-Villaverde (2005) also fall in this class, except that some of their models are quality-ladder models rather than vintage models and some allow for fixed factors which neither Chari and Hopenhayn (1991) nor I model explicitly. Yet another technology-choice model is Jovanovic and Nyarko (1996). All these papers relate to mine because they ask a question similar to the one I ask here, namely, when does an economy

\footnotetext{
*I thank Jess Benhabib, Michele Boldrin, Bart Hobijn, Hyeok Jeong, Matthias Kredler, Omar Licandro, Dmitriy Stolyarov, Gianluca Violante, and especially Jeremy Greenwood for comments and the NSF and the Marion Ewing Kauffman Foundation for support.

${ }^{\dagger}$ New York University.
} 
switch to a technology of a new vintage, i.e., how long do agents keep investing in old technologies after a new technology becomes available. Therefore this literature asks the question literature asks the question whether agents should use the new technology, old technologies, or both?

The question of old versus new comes up in a non-trivial way even in the traditional one-capital model. The traditional one-capital production function has capital of different vintages aggregated by the perpetual inventory method; the elasticity of substitution between the different vintages of capital is infinite. ${ }^{1}$ Nevertheless, in this model a sufficient price decline for the old capital can induce agents to buy used capital and then agents face the decision - do I buy new capital, old capital, or both?

A related literature exists dealing with substitution in tastes as opposed to production. Koeniger and Licandro (2006) find that as the elasticity of substitution in utility rises, resources shift towards the most productive sectors. This is similar to my finding that a higher elasticity of substitution in production shifts the distribution of capital in use towards the most productive, i.e., towards the latest vintages.

There are, however, plenty of examples where old and new capital are not perfect substitutes and where they may instead complement one another to an extent. New machinery is usually housed in an older building, and therefore work such as Gort, Greenwood and Rupert (1999) that differentiates structures from equipment implicitly also deals with a production function that includes capital of different vintages between which the elasticity of substitution is finite. Other examples are the renovation of an old structure with a new HVAC system, putting new software on an old computer, and retro-fitting a new restaurants. And the same vintage of the 'VW Beetle' was produced in Mexico from 1964 to 2003.

This paper seeks to answer the question of how investment in new vintages vs. old vintages depends on the elasticity of substitution in production and on other parameters. It assumes that the production function is CES in the capital stocks of different vintages. We find, not at all surprisingly, that when the elasticity is high enough, firms will not invest in old-vintage capital, but only in new capital. But when the elasticity drops to a critical level, firms will wish to invest in old capital. We shall derive this critical level under the assumption that the interest rate is constant.

Neither Benhabib and Rustichini (1991, 1992) nor Chari and Hopenhayn (1991) derive such a condition in their models. Just as I do here, Chari and Hopenhayn (1991) analyzed only a steady state, and the same forces are at work in their model as operate here. The condition we shall derive, (11), involves four parameters, and each operates in an intuitive way. Let us refer to Figure 1. It turns out that investment in old capital is more likely if

1. The elasticity of substitution, $\sigma$, between old and new capital is low - this makes old capital more essential to production. This was already suggested by the simulation results displayed in Figure 1 of Chari and Hopenhayn;

\footnotetext{
${ }^{1}$ See Section 5 for a treatment of models in this class.
} 


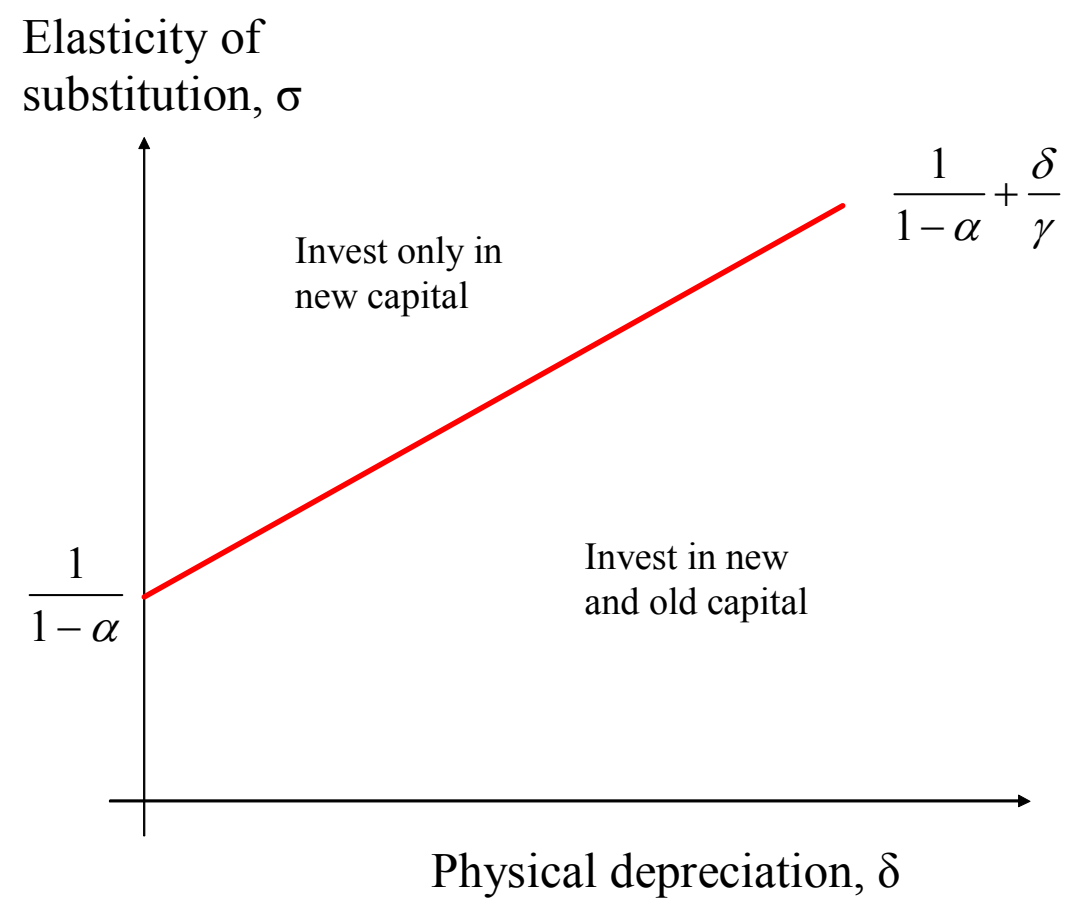

Figure 1: Illustration of condition (11)

2. Depreciation of capital, $\delta$, is high - this makes old capital wear away faster and replacement of that capital is more likely to be needed;

3. Technological progress, $\gamma$, is low - this means that new capital has little productive advantage over old capital - this too was suggested by Chari and Hopenhayn;

4. Returns to scale, $\alpha$, are high - this raises the firm's growth rate in response to a given rate of technological progress, which then brings in more capital, young and old alike.

Having derived the parameters under which the firm never wishes to invest in old technology, we shall then ask if realistic parameters lie in that set or not. We do know that in fact, investment in old capital occurs all the time, whether it is the renovation of old buildings or the production of new plant and equipment under an old design. From human-capital-based estimates of $\sigma \approx 0.5$, and $\alpha$ of anywhere upwards of 0.2 , we conclude that $\sigma$ is comfortably inside the South-East region of Figure 1. We also know that implication \#3, at least, is resoundingly confirmed by the historical time series: During the pre-industrial revolution era when growth was low, technologies took a long time to spread; that is, agents would for a long time 
invest in old technologies. Boddy and Gort (1971) discuss the substitution of old capital for new capital with special reference to structures which are older than the equipment that they house.

A closely related paper is that of Aruga (2007) who asks the same question when does a firm invest in capital of older vintages - though in a very different model. Aruga shows that when each vintage production function requires two complementary capital stocks that depreciate at different rates, investment in old capital is optimal when it allows to efficiently utilize the undepreciated stock of complementary capital (like writing new software for old computers instead of throwing the old computers out). ${ }^{2}$ Since I assume that all capital depreciates at the same rate, Aruga's results and mine are complements.

We shall begin at the partial equilibrium level, since we are interested in describing a firm's production function and a firm's optimal investment behavior. In section 2 we shall deal with the decision problems of firms that take the rate of interest, $r$ as exogenously given. We shall close the model in Section 3 and derive the equilibrium interest rate. Section 4 offers some conjectures on investment policies that would be optimal when the growth rate is not constant. Section 5 deals independently with what otherwise is a special case that arises when the elasticity of substitution is infinite - the efficiency-units approach of Jorgenson (1964) and Greenwood, Hercowitz and Krusell (1997) - and shows that the two approaches lead to the same investment policy and growth rate. Finally, Section 6 concludes the paper.

\section{Model}

A firm's or an economy's output depends on the sequence of capital stocks $\left(k_{v, t}\right)_{v=-\infty}^{v=t}$ and possibly other factors. Here $k_{v, t}$ is the amount of capital of vintage $v$ at date $t$. For instance (and henceforth we ignore other factors of production), one may take the form

$$
y=\left(\int_{-\infty}^{t} k_{v, t}^{\beta} d v\right)^{\alpha / \beta}
$$

where

$$
0<\alpha<1 \quad 0<\beta<1 .
$$

All capital depreciates at the constant rate $\delta$. There is no technology for converting one vintage of capital into another ${ }^{3}$, and capital cannot be consumed. Therefore the scrap value of capital is zero.

\footnotetext{
${ }^{2}$ Aruga's Proposition 1(i) states that if embodied technological progress is sufficiently slow when compared to the differential in the depreciation rates of the two types of capital, then investment in old-vintage capital will be optimal.

${ }^{3}$ See Boldrin and Fernandez-Villaverde (2005) and Jovanovic and Rousseau (forthcoming) for models that allow for such a conversion technology. Comin and Hobijn (2006) allow full reversibility of investment - selling the machine allows the recovery of the full cost of making it.
} 
The elasticity of substitution.-The elasticity of substitution in production is

$$
\sigma=\frac{1}{1-\beta}
$$

Note that we assumed that $\beta>0$ which means that $\sigma$ exceeds unity.

The case of $\beta<0$.- In the Cobb-Douglas case in which $\beta=0$ and $\sigma=1$, the firm will have to invest in old capital if it is to produce output as $t$ gets large. It follows, then, that the same will be true when $\beta<0$, i.e., when $\sigma<1$, new and old capital are more complementary than Cobb Douglas. Therefore the relevant $\beta$ values for which the firm will not invest in old capital will in any case have to be positive, and so the restriction in (2) does not limit the analysis in any way. ${ }^{4}$ That is why (10) is also valid for all $\beta \leq 0$, and (11) is valid for $0 \leq \sigma \leq 1$.

The accumulation of capital of different vintages. - In general firms will invest in old-vintage capital. We seek conditions under which this is true. To derive these conditions we proceed as follows:

1. Assume all investment is in new capital

2. Derive necessary and sufficient conditions for this investment pattern to be optimal along a constant-growth path.

This procedure makes the analysis simple, but limits the results to constant growth.

Since all investment is, by assumption, always in frontier capital, we do not need to label investment, $x_{t}$, by its type. The law of motion for $k$ then is

$$
\frac{d k_{v, t}}{d t}=-\delta k_{v, t}
$$

Then

$$
k_{v, t}=e^{-\delta(t-v)} z_{v} x_{v}
$$

Technological progress.-We assume that the efficiency of date $t$ investment is $z_{t}$. We assume throughout that the price of capital is unity, that the unit investment delivers $z_{t}$ efficiency units of capital.

\footnotetext{
${ }^{4}$ The Chari-Hopenhayn specification implies that if the elasticity of substitution is one or less, the wage paid to the young generation is zero - see their equation (5) and the sentence below.
} 


\subsection{The firm's problem}

Consider the problem of a firm that (for now) is not allowed to invest in past vintages of capital. Its output at date $t$ is

$$
y_{t}=\left(\int_{-\infty}^{t}\left(e^{-\delta(t-v)} z_{v} x_{v}\right)^{\beta} d v\right)^{\alpha / \beta}
$$

where $\alpha \leq 1$. The firm solves

$$
\max _{(x)_{t}^{\infty}} \int_{0}^{\infty} e^{-r t}\left(y_{t}-x_{t}\right) d t
$$

subject to the initial condition that the distribution of capital over past vintages $(t \leq 0)$ at date zero is given. Since there are no adjustment costs, the FOC says that the cost of capital must equal its discounted marginal product:

$$
1=\int_{t}^{\infty} e^{-r(s-t)} \frac{\partial y_{s}}{\partial x_{t}} d s
$$

Now, since $\frac{\alpha}{\beta}-1=\frac{\alpha}{\beta}\left(1-\frac{\beta}{\alpha}\right)=\frac{\alpha}{\beta}\left(\frac{\alpha-\beta}{\alpha}\right)$,

$$
\frac{\partial y_{t}}{\partial x_{v}}=\alpha e^{-\beta \delta(t-v)} z_{v}^{\beta} \frac{y_{t}^{\frac{\alpha-\beta}{\alpha}}}{x_{v}^{1-\beta}}
$$

Substituting in for $\frac{\partial y_{t}}{\partial x_{v}}$, we have

$$
1=\alpha z_{t}^{\beta} x_{t}^{\beta-1} \int_{t}^{\infty} e^{-(r+\beta \delta)(s-t)} y_{s}^{\frac{\alpha-\beta}{\alpha}} d s
$$

Procedure.-We make the constant-growth assumptions for $z_{t}=e^{\gamma t}$. We use the method of undetermined coefficients. i.e., assume that

$$
x_{t}=x_{0} e^{\lambda t}
$$

and solve for $\lambda$. Then we get for output:

$$
\begin{aligned}
& y_{t}=\left(\int_{-\infty}^{t}\left(e^{-\delta(t-v)} z_{v} x_{v}\right)^{\beta} d v\right)^{\alpha / \beta} \\
& y_{t}=\underbrace{[\beta(\delta+\gamma+\lambda)]^{-\alpha / \beta}}_{=C_{y}} e^{\alpha(\gamma+\lambda) t} x_{0}^{\alpha}
\end{aligned}
$$

The faster the investment technology and investment grow, the higher the growth rate. At $t=0$ and for fixed $x_{0}$, the level is decreasing in $\delta$ (stuff depreciates away), 
in $\gamma$ (high $\gamma$ means lower investment technology levels for $t<0$ since we fixed it to 1 at $t=0$ ) and also decreasing in $\lambda$ (the logic is just like for $\gamma$ ).

Now we substitute the solution for output back into the FOC for investment (the second equation) - the first states our undetermined coefficients again, taken to the power $(1-\beta)$ :

$$
\begin{aligned}
x_{t}^{1-\beta} & =x_{0}^{1-\beta} e^{(1-\beta) \lambda t} \\
x_{t}^{1-\beta} & =\alpha \underbrace{e^{\beta \gamma t}}_{=z_{t}^{\beta}} x_{0}^{\alpha-\beta} C_{y}^{\frac{\alpha-\beta}{\alpha}} e^{(r+\beta \delta) t} \int_{t}^{\infty} \exp \{-(\underbrace{r+\beta \delta-(\alpha-\beta)(\gamma+\lambda)}_{\equiv A}) s\} d s \\
& =\alpha e^{\beta \gamma t} x_{0}^{\alpha-\beta} C_{y}^{\frac{\alpha-\beta}{\alpha}} e^{(r+\beta \delta) t} \frac{e^{-A t}}{A} .
\end{aligned}
$$

We need $A>0$ for this to be finite, which it is whenever $\alpha<\beta$, i.e., whenever decreasing returns are sufficiently small to override complementarity in the vintages.

Proposition 1 In the steady state $x$ and $y$ both grow at the rate

$$
\lambda \equiv \frac{\alpha}{1-\alpha} \gamma
$$

Proof. Growth of $x$.- The undetermined growth rate, $\lambda$, of $x$ then satisfies

$$
\begin{aligned}
(1-\beta) \lambda & =\beta \gamma+r+\beta \delta-A=\beta \gamma+(\alpha-\beta)(\gamma+\lambda) \\
& =\alpha(\gamma+\lambda)-\beta \lambda
\end{aligned}
$$

which leads to (7). Growth of $y$.- If $x$ grows at the rate $\lambda$, then $y$ grows at the rate

$$
\alpha(\lambda+\gamma)=\alpha\left(\frac{\alpha}{1-\alpha} \gamma+\gamma\right)=\frac{\alpha}{1-\alpha}(\alpha \gamma+[1-\alpha] \gamma)
$$

which again leads to (7).

Surprisingly, perhaps, growth does not depend on $\beta$, and is the same as the growth rate we derived in (18) as it should be. Otherwise the expression is intuitive: The faster $z$ grows, the faster the firm invests, and the weaker are the decreasing returns in production, (i.e. the closer $\alpha$ is to 1 ), the faster investment grows.

Level of $x$ and $y$.- Now, substitute into the constants $C_{y}$ and $A$ to get

$$
\gamma+\lambda=\frac{1}{1-\alpha} \gamma, \quad C_{y}=\left[\beta\left(\delta+\frac{\gamma}{1-\alpha}\right)\right]^{-\frac{\alpha}{\beta}}, \text { and } \quad A=r+\beta \delta-\frac{\alpha-\beta}{1-\alpha} \gamma
$$

so that

$$
x_{0}^{1-\alpha}=\frac{\alpha C_{y}^{\frac{\alpha-\beta}{\beta}}}{A}=\frac{\alpha\left[\beta\left(\delta+\frac{\gamma}{1-\alpha}\right)\right]^{\frac{\beta-\alpha}{\beta}}}{r+\beta \delta-\frac{\alpha-\beta}{1-\alpha} \gamma}
$$


In the special case for which $\beta=1$,

$$
x_{0}^{1-\alpha}=\frac{\alpha\left(\delta+\frac{\gamma}{1-\alpha}\right)^{1-\alpha}}{r+\delta+\gamma},
$$

and this is the same expression as we got in (19), as it should be.

\subsection{When does the firm invest in old-vintage capital?}

So far we assumed that the firm had to invest in frontier technology only. Is this a binding constraint? We know that it does not bind when the $k$ 's are perfect substitutes up to a change of units, i.e., when $\beta=1$ which implies that the elasticity of substitution $\sigma=\frac{1}{1-\beta}=+\infty$. It turns out that there is a range of values of $\beta$ for which the firm would not invest in past technologies.

Proposition 2 The firm invests in old technologies if and only if the elasticity of substitution of the capital inputs is sufficiently low; that is, if and only if

$$
\beta<\frac{\gamma \alpha+\delta(1-\alpha)}{\gamma+\delta(1-\alpha)}
$$

Proof. The FOC (6) is met at date $t$. The firm will not wish to invest in date- $t$ technology ever again if the RHS of (6) declines over time. But the RHS can be written as

$$
e^{\gamma t} x_{t}^{\beta-1} y_{t}^{\frac{\alpha-\beta}{\alpha}} \int_{t}^{\infty} e^{-(r+\beta \delta)(s-t)} e^{(\alpha-\beta) \gamma(s-t)} d s
$$

The term $e^{\gamma t}$ does not change over time because the efficiency of creating the type- $t$ capital does not change. If the firm does not ever again invest in technology $t, x_{t}$ shrinks at the rate $\delta$. On the other hand, $y$ grows at the rate $\alpha \lambda=\frac{\alpha}{1-\alpha} \gamma$. The integral does not depend on $t$, whereas $x_{t}^{\beta-1} y_{t}^{\frac{\alpha-\beta}{\alpha}}$ grows at the rate

$$
\delta(1-\beta)+\gamma \frac{\alpha-\beta}{1-\alpha},
$$

which is negative if and only if (10) holds.

The RHS of (10) is less than one whenever $\alpha<1$, and therefore there is a neighborhood around 1 for $\beta$ for which the firm invests only in the newest vintage. Also, the RHS of (10) is increasing in $\alpha$, making the condition harder to satisfy at higher values of $\alpha .^{5}$

\footnotetext{
${ }^{5}$ Condition (10) can also be written as

$$
\beta<\frac{\delta+\lambda \alpha}{\delta+\lambda}
$$
}

where $\lambda$ is the growth rate of output. The RHS is increasing in $\alpha, \lambda$, and $\delta$. 


\subsubsection{Re-stating (10) in terms of the elasticity of substitution}

A simpler condition emerges when we state (10) in terms of the elasticity of substitution in production, $\sigma=\frac{1}{1-\beta}$. Since $\beta=1-\frac{1}{\sigma}$, (10) reads

$$
\frac{1}{\sigma}>1-\frac{\gamma \alpha+\delta(1-\alpha)}{\gamma+\delta(1-\alpha)}=\frac{\gamma(1-\alpha)}{\gamma+\delta(1-\alpha)} .
$$

Thus we conclude that investment in old capital takes place if

$$
\sigma<\frac{\delta}{\gamma}+\frac{1}{1-\alpha}
$$

This is our main result, and we discussed its plausibility in the introduction; a few more remarks here:

- A high $\gamma$ discourages investment in old capital by making new capital more attractive. As $\gamma$ tends to zero, the vintages become exchangeable in the production function and investment in old capital must take place as long as there's any complementarity among the vintages.

- The effect of $\alpha$ appears to work through the growth rate, $\frac{\alpha}{1-\alpha} \gamma$. Fixing $\gamma$ fixes the advantage of new vintages relative to old vintages. As $\alpha$ rises, the rate of growth rises and this draws investment in old vintages.

- The elasticity of substitution between different vintages of $k$ differs from Chari's and Hopenhayn's concept of substitution between capital of different ages within the same technological vintage. ${ }^{6}$ Nevertheless, a lower $\sigma$ prolongs the period of investment in old technologies in both their paper and this one.

\section{General equilibrium and growth}

We found that the growth rate of the firm's output does not depend on $r$ and $\beta$, but that the level effect on investment, derived in (9) depended on both parameters.

Market organization.-Because of diminishing returns $(\alpha<1)$, we shall assume an exogenous number of firms that we shall normalize to a unit mass.

Preferences and saving.-Utility is homothetic and capital markets are perfect. Then the distribution of income does not affect the total amount saved and consumed. We therefore imagine an agent that at date zero owns the average wealth, call it $W$, in the economy, and we shall determine conditions for the optimal time path of per

\footnotetext{
${ }^{6}$ Also, their paper is about human, not physical capital and has only two capital inputs, "experienced" and "inexperienced."
} 
capita consumption of the final good, $c_{t}$. Capital markets are perfect, with the interest rate being $r$. The agent maximizes lifetime utility

$$
\int_{0}^{\infty} e^{-\rho t} U\left(c_{t}\right) d t .
$$

where $U(c)=\frac{c^{1-\theta}}{1-\theta}$ subject to the lifetime constraint

$$
\int_{0}^{\infty} e^{-r t} c_{t} d t \leq W
$$

The first-order conditions for this problem yield consumption growth equal to $(r-\rho) / \theta$. But since consumption must grow at the same rate as income,

$$
\frac{r-\rho}{\theta}=\frac{\alpha}{1-\alpha} \gamma
$$

whence we get the equilibrium level of $r$ as

$$
r=\rho+\frac{\alpha \gamma \theta}{1-\alpha}
$$

Thus $\beta$ affects neither the rate of growth nor the rate of interest.

\section{Possible extensions}

Two obvious directions are left unexplored here: Heterogeneity and off-steady-state dynamics.

\subsubsection{Heterogeneity}

The model assumes that firms are all the same. If investment in old capital does occur, it is because different vintages are complements in the representative firm's production function. We may wish to extend the results to heterogeneous firms. Paradoxically, perhaps, when trading of used capital is possible, old capital is less likely to be produced. The models of used-capital trading by Jovanovic (1998), Stolyarov (2002), and Licandro, Puch and Sampayo (2006) all involve investment in new capital that, as it ages, is then passed down from rich to poor customers. But while there is continual purchase of old capital by some firms or households, there is never production of vintage capital - only the latest vintage is produced at each date.

If used-capital markets cannot function well, perhaps because of informational frictions, then if some agents or firms have a special need for vintage capital, that need would have to be satisfied by new production of vintage capital. 


\subsubsection{Conjectures on off-steady-state dynamics}

Having gone through the derivations we may conjecture what will happen off the constant-growth path. We may seek conditions under which investment in old capital will happen (i) Sometimes and (ii) Always.

1. Investment in old capital sometimes. - One would expect that investment in old capital will happen at some dates even under conditions weaker than (10). In a recession there may be little or no investment. Later, when the recession is over, capital of the recession-era vintage will be scarce, and firms will want to obtain some.

2. Investment in old capital always. - Conditions stronger than (10) would be needed for this to be true. As Benhabib and Rustichini (1992, p. 2) point out, a high level of past investments in capital of a given type will reduce the current level of investment in that type of capital. In a boom there may be a lot of investment in the capital of a given vintage. When the boom is over, capital of the boom vintage will be plentiful when compared to younger-vintage capital, and firms would not always want to augment it.

Adda and Cooper (2000) analyze transitional dynamics in a model in which only the latest vintage of capital is produced, and Cooper and Haltiwanger (1993) analyze the case where there is no technological progress but where there are shocks and a fixed costs of adjusting capital. Kremer and Thomson (1998) study the convergence properties of a Chari-Hopenhayn type of OLG model and argue that convergence can take a long time, even for fairly values of the elasticity of substitution between different vintages of skill.

\section{Evidence on (11)}

Choosing reasonable values for the parameters on the RHS of (11).- As $\alpha$ becomes unity or as $\gamma$ goes to zero, (11) holds for all $\sigma<\infty$. Evidence on returns to scale is that they are thought to be close to constant, and a value $\alpha=0.85$ would be about as low as one could reasonably go. From (7) we see that if we set output growth at 0.02 , we would then need to have $\gamma=0.004$. It also is reasonable to set $\delta$ at 0.08 . In that case (11) reads

$$
\sigma<26.7 \text {. }
$$

One can entertain other parameters. For instance if, instead of (1) we were to include raw labor and write

$$
y=\left(L^{1-\phi}\left(\int_{-\infty}^{t} k_{v, t}^{\beta} d v\right)^{\phi / \beta}\right)^{\alpha_{0}} .
$$


In a closed economy with a fully-employed labor force, $L$ would be given, and then it would be reasonable to interpret $\alpha \approx \phi \alpha_{0}$. In that case, using information on factor shares and what we know about span of control, we could get $\alpha$ to be as low as 0.2 . Nevertheless, any reasonable set of values for the parameters in (12) would produce a value for RHS of (11) of at least 5. As we shall see, however, the estimates we have for $\sigma$ are an order of magnitude below that, and so clearly the model leads us to the conclusion that we should see investment in old vintages of capital.

\subsection{Evidence on technology adoption}

While (11) seems to hold in practice, we would like to know how slack the inequality is. But there are different degrees with which (11) may hold - is there any evidence that diffusion is slower when (10) is more extremely satisfied? A second reason why we should expect (11) to hold is that we observe firms investing in old technologies and old capital, and that the penetration of a technology is gradual and S shaped. If (11) or, equivalently, (10) did not hold, technological diffusion would be instantaneous: Technology would reach its maximal penetration immediately. After its immediate introduction capital thereafter would slowly depreciate and asymptote to zero - contrary to the evidence. A higher $\gamma$ indicates a speedier technology cycle.

Next, it seems that there exist ideal proportions between old and new vintages of ships: A telling example concerns steam ships and diesel ships. During World War II, the Germans lost many more internal-combustion-driven ships than steam ships. Yet, by 1965 the proportions of motor and steam ships had reverted to the proportions prevailing in the fleets of the four Scandinavian countries none of which had had nearly as large a fraction of their fleets destroyed during the war. This is depicted in Figure 6 of Comin and Hobijn (2004).

\subsection{Labor-market evidence}

We have some estimates on $\sigma$ for vintage human capital. Jeong and Kim (2007) estimated the elasticity of substitution between raw labor, L, and a multi-period-based index of labor-market experience. Wages are assumed to come from the production function

$$
y=\left(a L^{\beta_{0}}+(1-a)\left(\sum_{j \leq t} k_{j}\right)^{\beta_{0}}\right)^{1 / \beta_{0}}
$$

where the $k_{j}$ are quantities of experience accumulated in vintage $j$ and adjusted for quality. Without going into the details of how they calculate the $k_{j}$, suffice it to say that the index of vintage human capital is a linear, quality-adjusted weighted average of past experience levels, and so the parameter $\beta_{0}$ in (13) is not quite the same as the parameter $\beta$ in (1). Nevertheless $\beta$ and $\hat{\beta}$ measure should be fairly close to each other. 
In a variety of data sets these authors estimate $\beta_{0}$ to be negative, i.e., an elasticity of substitution below unity. For Thailand the estimated elasticity of substitution was

$$
\hat{\sigma} \equiv \frac{1}{1-\hat{\beta}_{0}}=0.42
$$

for the modern sector and only $\hat{\sigma}=0.08$ for the traditional sector. Jeong, Kim and Manovskii (2007) analyze the U.S. data and they assume only one "modern" technology for which they give two point estimates. The first is identified from the time-series variation of the aggregate experience to labor ratio (as in the Jeong-Kim paper) and the second from the cross section using differences in the experience to labor ratio across US states. The first gives $\hat{\sigma}=0.46$ and the second estimate is $\hat{\sigma}=0.47$. The standard errors are quite low, and so based on these estimates we would say that the left-hand side of (11) is around 0.5 whereas we concluded above that the right-hand side is at least 5. Therefore the human-capital-based $\sigma$ seems to be well inside the south-east region in Figure 1.

Since experience leads to the accumulation of some kind of skill, the evidence on the elasticity of substitution of skilled and unskilled labor should also be of relevance. Katz and Murphy estimate the elasticity of substitution between high-school labor (their "unskilled" labor) and college labor (their "skilled" labor) and the estimated value is 1.4. Krusell et al. (2000) estimate the elasticity of substitution between high-school labor (their "unskilled" labor) and college labor (their "skilled" labor) at 1.7. Though above unity, these estimates still are several times the likely value of the RHS of (11).

The human capital evidence must be interpreted with caution because older vintages of labor may be more productive due to experience. Physical capital also may become more productive with age if there is a learning curve associated with its adoption, as would be the case if equipment needs to be debugged and made user friendly.

\section{A consistency check: The efficiency-units ap- proach}

It is instructive to look separately at the standard way of writing the production function in which capital appears as an aggregate, a sum of depreciated efficiency units created at various dates in the past. Equation (16) below is an example of what we mean. In this case the elasticity of substitution between capital of different vintages is infinite. We shall solve this case independently, however, and then show that the answers independently, so that this section can also be seen as a way of checking our previous results for the case in which $\beta=1$.

Even in this model, however, if old capital falls in price it can trade on the usedcapital market and, if the cost of producing it falls, we will see newly-produced 
old-vintage capital. In other words, whether old capital is used also depends on its cost relative to new capital. The original version of Greenwood, Hercowitz and Krusell $(1992,1997)$ was a vintage capital model that made this point in its Figure 4. The idea is simply that if old capital is cheap enough one will buy it, even when it substitutes perfectly with new capital. As pointed out in the introduction, even if old-vintage capital cannot be produced (perhaps the recipe is "forgotten" or the specialized inputs are no longer available as may be the case with old architecture), old capital can and does trade on the used capital market at the discount deemed sufficient. ${ }^{7}$

In this currently popular version of the vintage-capital model, because the elasticity of substitution between the different capital stocks is infinite, all investment is in the latest-vintage capital. This is the approach to vintage capital that Domar (1963), Jorgenson (1966), and Greenwood, Hercowitz and Krusell (1997) take. For completeness I shall now show that when $\beta=1$, the model is quite consistent with this approach. Thus in Jorgenson (1966) and Greenwood et al. (1997), e.g., the argument in the production function is average efficiency of capital.

Let output depend on the number of efficiency units of capital, $K$ so that

$$
y=F(K) \text {. }
$$

Let

$$
\frac{d K_{t}}{d t}=-\delta K_{t}+z_{t} x_{t}
$$

where $x_{t}$ is the number of machines purchased at date $t$. Then

$$
K_{t}=\int_{-\infty}^{t} e^{-\delta(t-v)} z_{v} x_{v} d v
$$

It is seen that if $F(K)=K^{\alpha}$, then (14) and (16) are equivalent to (1) when $\beta=1$.

For the production function (14), and for most other purposes, an equivalent way to proceed would be to assume that all vintages of capital are homogeneous and that it is just the price, $q_{t} \equiv 1 / z_{t}$, of a unit of capital that declines over time.

The firm's problem.-The firm solves

$$
\max _{(x)_{t}^{\infty}} \int_{0}^{\infty} e^{-r t}\left(y_{t}-x_{t}\right) d t
$$

\footnotetext{
${ }^{7}$ Interpreting the discount at which old capital trades is not so easy. The discount may reflect wear and tear ("depreciation") which in the one-capital model is interpretable as $e^{-\delta A}$, where $A$ is the age of the capital but not any change in the price of an efficiency unit of capital relative to the consumption good. Or it may reflect a change in the price of the market value of old capital relative to the consumption good ("obsolescence"), as typically occurs in the vintage-capital model in which old capital falls in price when a new capital can be produced more cheaply. Hulten and Wykoff (1981) recognize the distinction in their first footnote, but in their concluding paragraph they admit that they cannot disentangle the two effects. Gort, Greenwood and Rupert (1999) achieve identification in reaching their eq. (2.26) by assuming that structures do not physically depreciate because they must be perfectly maintained.
} 
subject to (14), (16) and subject to $K_{0}$ being given. There are no adjustment costs, and so the FOC equates the cost of capital to its discounted marginal product.

$$
1=z_{t} \int_{t}^{\infty} e^{-(r+\delta)(s-t)} F^{\prime}\left(K_{s}\right) d s
$$

Now let the production function be of the form

$$
F(K)=A K^{\alpha}
$$

Then the FOC reads

$$
1=\alpha e^{\gamma t} \int_{t}^{\infty} e^{-(r+\delta)(s-t)} K_{s}^{\alpha-1} d s .
$$

To solve for the optimal path we guess that $K$ grows at a constant rate, $\mu$, plug this guess into the FOC and solve for $\mu$. This is the "undetermined coefficients" method. Thus let

$$
K_{t}=K_{0} e^{\mu t}
$$

Then

$$
\begin{aligned}
1 & =\alpha e^{\gamma t} \int_{t}^{\infty} e^{-(r+\delta)(s-t)}\left(K_{t} e^{\mu(s-t)}\right)^{\alpha-1} d s \\
& =\alpha e^{\gamma t} K_{t}^{\alpha-1} \int_{t}^{\infty} e^{-(r+\delta+\mu[1-\alpha])(s-t)} d s \\
& =\frac{\alpha e^{\gamma t}}{r+\delta+\mu(1-\alpha)} K_{t}^{\alpha-1},
\end{aligned}
$$

so that

$$
K_{t}=\left(\frac{\alpha e^{\gamma t}}{r+\delta+\mu(1-\alpha)}\right)^{1 /(1-\alpha)}
$$

\subsection{Growth}

From (17), the growth of $K$ is

$$
\mu=\frac{1}{1-\alpha} \gamma
$$

so that since $y=K^{\alpha}$, the growth of $y$ is

$$
\alpha \mu=\frac{\alpha}{1-\alpha} \gamma
$$

Now $x$ grows more slowly than $K$. To derive $x$ we use (15)

$$
z_{t} x_{t}=\delta K+\frac{d K}{d t}=\left(\delta+\frac{\gamma}{1-\alpha}\right) K
$$


Dividing both sides by $z_{t}$, we have

$$
\begin{aligned}
x_{t} & =\left(\delta+\frac{\gamma}{1-\alpha}\right) K e^{-\gamma t} \\
& =\left(\delta+\frac{\gamma}{1-\alpha}\right)\left(\frac{\alpha}{r+\delta+\mu(1-\alpha)}\right)^{1 /(1-\alpha)} \exp \left(\left[\frac{1}{1-\alpha}-1\right] \gamma t\right)
\end{aligned}
$$

Therefore $x$ grows at the rate

$$
\frac{\alpha}{1-\alpha} \gamma=\alpha \mu
$$

which is the same as the expression in (7). Substituting for $\mu$ into the previous expression and evaluating it at $t=0$ yields

$$
x_{0}^{1-\alpha}=\frac{\alpha\left(\delta+\frac{\gamma}{1-\alpha}\right)^{1-\alpha}}{r+\delta+\gamma} .
$$

\section{Conclusion}

This paper has analyzed the optimal investment policy of a firm that faces a CES production function the inputs of which are capital stocks of different vintages. Filling a gap left by Benhabib and Rustichini (1991, 1992), Chari and Hopenhayn (1991) and others, the paper states the parameter configuration under which investment in old vintages actually would take place. This restriction is stated in Proposition 2, and then re-stated more conveniently in (11).

The restriction is valid only for a deterministic economy that grows at a constant rate. When the firm's investment rate fluctuates, the conditions for ensuring that investment in old capital occurs sometimes would be weaker, and the conditions under which it would occur always would be stronger. The economy also has no fixed factor, and therefore no country or location has a natural advantage in buying new capital as opposed to old.

A limitation of the result is its qualitative nature. It tells us if investment in old capital will occur, but it does not say how much. In other words, it tells us when the distribution of capital by vintage will be non-degenerate, but it does not say anything about the shape of that distribution. On this dimension it is likely that we shall have to continue to rely on the computer. Benhabib and Rustichini (1992) and Chari and Hopenhayn (1991) have already simulated their economies. Condition (11) should be a useful complement to such simulations.

The paper also have not analyzed the effect of heterogeneity. Finally, technological progress is throughout assumed to be exogenous. If invention requires the sacrifice of resources, the speed with which new technologies gain market share will in general affect the rate of technological progress. 


\section{References}

[1] Adda, Jérôme and Russell Cooper. "Balladurette and Juppette: A Discrete Analysis of Scrapping Subsidies." Journal of Political Economy 108, No. 4 (August 2000): $778-806$.

[2] Aruga, Osamu. "Conventional or New? Optimal Investment Allocation across Vintages of Technology." Ministry of Education, Japan, November 2007.

[3] Benhabib, Jess and Aldo Rustichini. "Vintage Capital, Investment and Growth." Journal of Economic Theory 55 (1991): 323-339.

[4] Benhabib, Jess and Aldo Rustichini. "A Vintage Model of Growth and Investment: Theory and Evidence." in General Equilibrium, Growth and Trade II, R. Becker et al., eds., Academic Press, San Diego, (1993): 248-300.

[5] Boddy, Raford and Michael Gort. "The Substitution of Capital for Capital." Review of Economics and Statistics 53, No. 2 (May 1971): 179-188.

[6] Boldrin, Michele and David K. Levine. "Growth Cycles and Market Crashes." Journal of Economic Theory 96, nos. 1-2 (January 2001): 13-39.

[7] Boldrin, Michele and David K. Levine. "Factor Saving Innovation." Journal of Economic Theory 105, no. 1 (2002): 18-41.

[8] Boldrin, Michele and Jesus Fernandez-Villaverde "A Theory of Growth Cycles." November 2005.

[9] Chari, V.V. and Hugo Hopenhayn. "Vintage Human Capital." Journal of Political Economy 99, no. 6 (December 1991): 1142-1165.

[10] Comin, Diego and Bart Hobijn. "Cross-Country Technology Adoption: Making the Theories Face the Facts." Journal of Monetary Economics 51, no. 1 (January 2004): 39-83.

[11] Comin, Diego and Bart Hobijn. "An Exploration of Technology Diffusion.", NBER Working Paper No. 12314, June 2006.

[12] Cooper, Russell and John Haltiwanger. "The Aggregate Implications of Machine Replacement: Theory and Evidence." American Economic Review 83, no. 3 (June 1993): 360-382.

[13] Domar, Evsey. "Total Productivity and the Quality of Capital." Journal of Political Economy 71, no. 6. (December 1963): 586-588. 
[14] Gort, Michael, Jeremy Greenwood, and Peter Rupert. "Measuring the Rate of Technological Progress in Structures." Review of Economic Dynamics 2, no. 1 (January 2003): 207-230.

[15] Greenwood Jeremy, Zvi Hercowitz and Per Krusell. "Long-run Implications of Investment-specific Technological Change." American Economic Review 87, no. 3 (June 1997): 342-362. The October 1992 version is at https://urresearch.rochester.edu/retrieve/5493/GHK1992.pdf

[16] Hulten, Charles and Frank Wykoff. "The Estimation of Economic Depreciation using Vintage Asset Prices : An Application of the Box-Cox Power Transformation." Journal of Econometrics 15, no. 3 (April 1981): 367-396.

[17] Jeong, Hyeok and Yong Kim. "Complementarity and Transition to Modern Economic Growth." mimeo, USC 2007.

[18] Jeong, Hyeok, Yong Kim, and Iourii Manovskii (2007), "Demographic Change and Relative Wages." mimeo, USC 2007.

[19] Jorgenson Dale. "The Embodiment Hypothesis." Journal of Political Economy 74, no. 1 (February 1966): 1-17.

[20] Jovanovic, Boyan and Yaw Nyarko. "Learning by Doing and the Choice of Technology." Econometrica 64, no. 6 (November 1996): 1299-1310.

[21] Jovanovic, Boyan. "Vintage Capital and Inequality." Review of Economic Dynamics 1, no. 2 (April 1998): 497-530.

[22] Jovanovic, Boyan and Peter L. Rousseau. "Mergers as Reallocation." Review of Economics and Statistics, forthcoming.

[23] Katz, Lawrence and Kevin Murphy. "Changes in Relative Wages, 1963-1987: Supply and Demand Factors." Quarterly Journal of Economics 107 (February 1992): 35- 78.

[24] Koeniger, Winfried and Omar Licandro. "On the Use of Substitutability as a Measure of Competition." Topics in Macroeconomics. Berkeley Electronic Press 6, no. 1 (2006): 1283-1283.

[25] Kredler, Matthias. "Experience vs. Obsolescence: A Vintage-Human-Capital Model." New York University, October 2007.

[26] Kremer, Michael and James Thomson. "Why Isn't Convergence Instantaneous? Young Workers, Old Workers, and Gradual Adjustment." Journal Journal of Economic Growth 3, no. 1 (March 1998): 5-23. 
[27] Krusell, Per, Lee Ohanian, Victor Rios-Rull, and Giovanni Violante. "CapitalSkill Complementarity and Inequality: A Macroeconomic Analysis." Econometrica 68, no. 5 (September 2000): 1029-1053.

[28] Licandro, Omar, Luis Puch, and Antonio Sampayo. "Secondhand market and the lifetime of durable goods." WP 2006-10, FEDEA, March 2006.

[29] Stolyarov, Dmitriy. "Turnover of Used Goods in Stationary Equilibrium: Are Older Goods Traded More?" Journal of Political Economy 110, no. 6 (December 2002): 1390-1413. 